\title{
Mevalonate-independent methylerythritol phosphate pathway for isoprenoid biosynthesis. Elucidation and distribution*
}

\author{
Michel Rohmer ${ }^{\ddagger}$ \\ Université Louis Pasteur/CNRS/Institut Universitaire de France, Institut Le Bel, \\ 4 rue Blaise Pascal, 67070 Strasbourg Cedex, France
}

\begin{abstract}
A long-overlooked metabolic pathway for isoprenoid biosynthesis, the mevalonateindependent methylerythritol phosphate (MEP) pathway, is present in many bacteria and in the chloroplasts of all phototrophic organisms. It represents an alternative to the well-known mevalonate pathway, which is present in animals, fungi, plant cytoplasm, archaebacteria, and some eubacteria. This contribution summarizes key steps of its elucidation and the state-ofthe-art knowledge of this biosynthetic pathway, which represents a novel target for antibacterial and antiparasitic drugs.
\end{abstract}

\section{INTRODUCTION: THE MEVALONATE PATHWAY FOR ISOPRENOID BIOSYNTHESIS}

Isoprenoids represent the most diverse family of natural products. They are all formally derived from the branched $\mathrm{C}_{5}$ skeleton of isoprene 1 (Fig. 1). Isopentenyl diphosphate 19 (IPP) and dimethylallyl diphosphate 20 (DMAPP) (Fig. 2) correspond both to the biological equivalents of isoprene. The elucidation of their biosynthesis resulted from the first applications of labeling with radioactive as well as stable isotopes and ended up in the discovery of the mevalonate pathway, which starts from acetate 12 activated as acetyl-coenzyme A 13 (Fig. 2). This first work on the early steps of isoprenoid biosynthesis was essentially performed with liver tissues and yeast for the biosynthesis of cholesterol and ergosterol (9, Fig. 1), and was later confirmed for the biosynthesis of plant sterols and triterpenes. Mevalonate 16 was thus accepted as the universal precursor of all isoprenoids in all living organisms $[1,2]$.

Discrepancies with this assertion were, however, reported. ${ }^{14} \mathrm{C}$-Labeled mevalonate was poorly incorporated into the carotenoids (e.g., 7, Fig. 1) from plant chloroplasts [3,4]. This was interpreted in terms of lack of permeability of chloroplasts toward mevalonate. In addition, incorporation yields of radiolabelled mevalonate into plant mono- and diterpenes were usually very low, at least as compared to those into sterols, which are synthesized in the cytoplasm [5]. Other data, which did not fit with the general occurrence of the mevalonate pathway, were obtained with mevinolin, a potent hypocholesterolemic agent, inhibiting the HMGCoA reductase, a key enzyme of the mevalonate pathway reducing hydroxymethylglutaryl-CoA 15 into mevalonic acid (MVA) 16. Mevinolin strongly inhibits sterol biosynthesis in plant systems, but had no effect on carotenoid and phytol biosynthesis [6,7]. Again, such negative results were interpreted in terms of impermeability of the chloroplast membrane toward the antibiotic. In addition, a cytoplasm-independent IPP biosynthesis was discovered in plant chloroplasts and chromoplasts [8]. All these contradictory results did not really question the accepted dogma of the

\footnotetext{
${ }^{*}$ Pure Appl. Chem. 75, 141-419 (2003). An issue of reviews and research papers based on lectures presented at the $23^{\text {rd }}$ IUPAC International Symposium on the Chemistry of Natural Products, Florence, Italy, 28 July-2 August 2002 on the theme of natural products.

ॠE-mail: mirohmer@chimie.u-strasbg.fr
} 


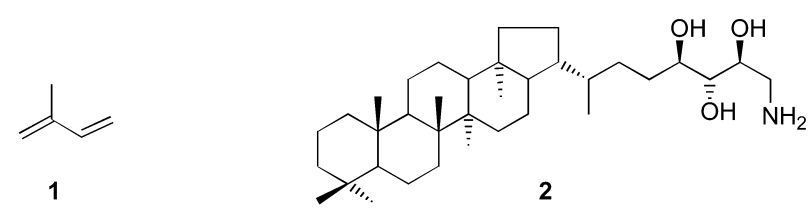<smiles>COC1=C(OC)C(=O)C(CC/C=C(\C)C(C)C)=C(C)C1=O</smiles>

3<smiles>CC1=C(C)C(=O)c2ccccc2C1=O</smiles>

4<smiles>CC1=CC(C)(CC=C(C)C(C)=CCO)C(C)=C(C)C1=O</smiles>

5<smiles>CC1=C(/C=C/C(C)=C/C=C/C(C)=C/C=C/C=C(C)/C=C/C=C(C)/C=C/C2=C(C)CCCC2(C)C)C(C)(C)CCC1</smiles>

7

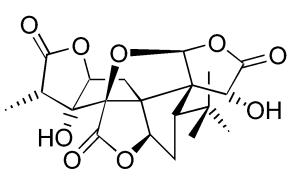

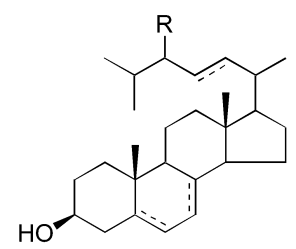

9

Fig. 1 Isoprenoids investigated for the elucidation of the MEP pathway: isoprene 1, bacterial hopanoid 2 , ubiquinone 3 , menaquinone 4 , phytol 5 , plastoquinone 6 , $\beta$-carotene 7 , ginkgolide 8 , sterol 9 .

mevalonate pathway, and the identity of the biosynthetic route followed for the biosynthesis of chloroplast isoprenoids.

\section{DISCOVERY OF THE MEVALONATE-INDEPENDENT METHYLERYTHRITOL PHOSPHATE PATHWAY IN BACTERIA}

As compared to plants, most bacteria are poor isoprenoid producers. All of them produce essential isoprene metabolites such as bactoprenol, the carbohydrate carrier for the biosynthesis of the peptidoglycane of the cell wall, or ubiquinone and/or menaquinone of the electron transport chains, but in rather tiny amounts. Accordingly, very few investigations were performed on the biosynthesis of bacterial isoprenoids. The few studies leading to positive results pointed to the presence of the MVA pathway. 


\section{GLYCOLYSIS}
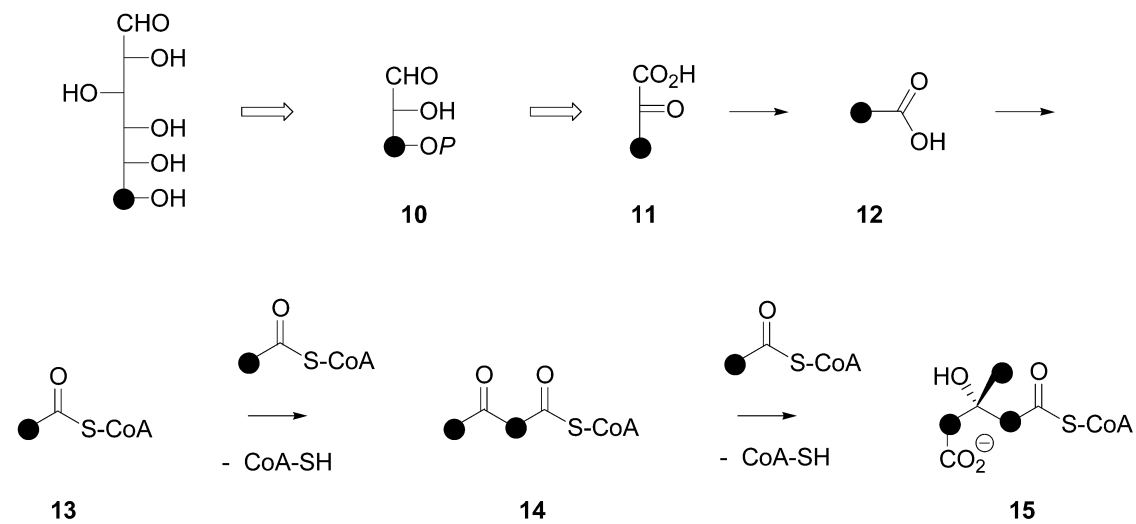

13

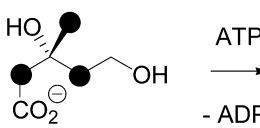

16
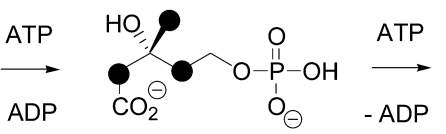

17

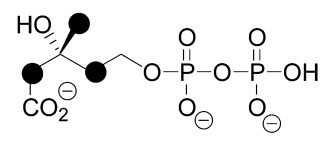

18
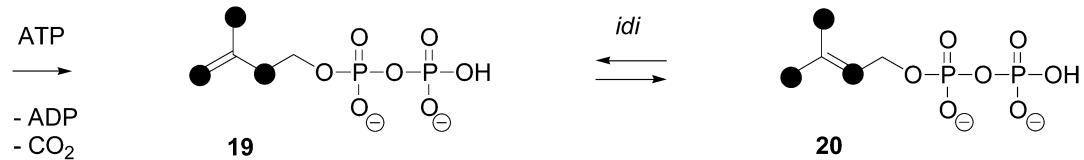

Fig. 2 MVA pathway for isoprenoid biosynthesis with labeling pattern from $\left[1-{ }^{13} \mathrm{C}\right]$ glucose metabolized via glycolysis.

${ }^{14} \mathrm{C}$ - and ${ }^{13} \mathrm{C}$-labeled MVA were respectively incorporated into a sterol of the gliding bacterium Nannocystis exedens [9] or into the carotenoids of a "Flavobacterium" sp. [10]. ${ }^{13} \mathrm{C}$-Labeled acetate was incorporated into the prenyl moiety of antibiotics of mixed origin from several actinomyces, and the labeling pattern corresponded to the expected one resulting from the direct incorporation of acetate into the MVA pathway [11]. Other incorporation attempts led to inconclusive results, which could not be readily interpreted. Thus, the incorporation of ${ }^{14} \mathrm{C}$-labeled acetate into the prenyl chain of ubiquinone from Escherichia coli resulted in a radioactivity distribution, which did not fit with the expected one from the MVA pathway, and led the authors to propose an alternative variant of this pathway via acetolactate [12]. ${ }^{13} \mathrm{C}$-Labeled acetate was not incorporated into this prenyl chain of ubiquinone, when E. coli was grown on a culture medium containing glucose and amino acid-derived carbon sources, whereas pyruvate labeled two contiguous carbon atoms derived from C3 and C5 of DMAPP or IPP [13]. Such results were indeed the premises for the presence of an alternative route for the formation of isoprene units.

The discovery of a novel pathway for the early steps of isoprenoid biosynthesis was indeed a sideproduct of our investigations on the biosynthesis of bacterial triterpenoids of the hopane series (e.g. 2, Fig. 1) [14]. $\mathrm{A}_{35}$ skeleton, in which the triterpenic hopane moiety is linked by a carbon/carbon bond to a polyhydroxylated $n$-alkyl side chain, characterizes all major bacterial hopanoids [15]. All bacteria do not produce hopanoids, but in the hopanoid-producing bacteria, such triterpenoids were shown to play a role of membrane stabilizers, much like sterol do in eukaryotic membranes. Hopanoid concen- 
tration is usually of the same order of magnitude as the sterol concentration in eukaryotic cells. This makes them well suited for investigation by NMR spectroscopy after feeding of ${ }^{13} \mathrm{C}$-labeled precursors. Feeding of ${ }^{13} \mathrm{C}$-labeled acetate to the hopanoid producing bacteria Rhodopseudomonas palustris, Rhodopseudomonas acidophila, or Methylobacterium organophilum were performed with bacteria grown on a mineral medium only containing ${ }^{13} \mathrm{C}$-labeled acetate as the only carbon and energy source [14]. Such experimental conditions ensured the incorporation of the labeled precursor into the hopanoids. As most biosynthetic pathways were known, a retrobiosynthetic analysis of the observed labeling patterns allowed reconstructing the reaction sequence involved in the formation of the hopanoids. Indeed, the experiments performed with $\left[1-{ }^{13} \mathrm{C}\right]$ - and $\left[2-{ }^{13} \mathrm{C}\right]$ acetate showed that the $\mathrm{C}_{5}$ side chain was derived from a D-pentose synthesized via the nonoxidative pentose phosphate pathway and linked to the triterpenic skeleton via its C5 carbon atom. The most interesting problem was, however, found in the isoprene moiety. The observed labeling pattern completely differed from the expected one from the MVA pathway. Interpretation was not obvious from the sole experiments performed with labeled acetate. The clues for the elucidation of this metabolic pathway were obtained after incorporation of glucose isotopomers with ${ }^{13} \mathrm{C}$ labeling either at $\mathrm{C} 1, \mathrm{C} 2, \mathrm{C} 3, \mathrm{C} 5$, or $\mathrm{C} 6$ into the hopanoids of Zymomonas mobilis [16]. Indeed, Z. mobilis only utilizes glucose as carbon source. This glucose is metabolized via the Entner-Doudoroff pathway. This bacterium does not possess a complete tricarboxylic acid cycle and does not convert pyruvate into glyceraldehyde phosphate because of the lack of an active enolase. From the observed labeling patterns, it could be deduced that isoprene units in the hopanoids were derived from a $\mathrm{C}_{2}$ subunit synthesized via pyruvate decarboxylation and from a $\mathrm{C}_{3}$ subunit corresponding to a triose phosphate derivative (Fig. 3) [16]. These results were in accordance with the formerly described incorporations of ${ }^{13} \mathrm{C}$-labeled acetate. The observed labeling pattern in the hopanoids from

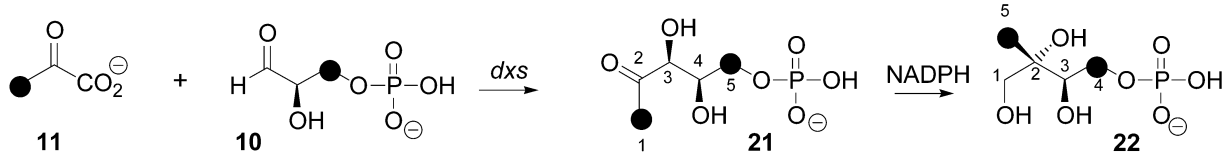

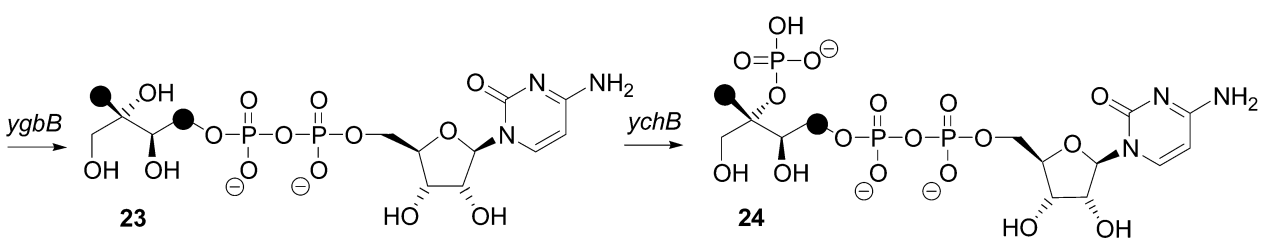<smiles>C=C(C)CCOP(=O)([O-])OP(=O)([O-])O[Mg]</smiles>

Fig. 3 MEP pathway for the biosynthesis of isoprenoids with labeling pattern from $\left[1-{ }^{13} \mathrm{C}\right]$ glucose metabolized via glycolysis. 
Rhodopseudomonas spp. or from M. organophilum simply resulted from the incorporation of acetate into the glyoxylate cycle, which allows growth on acetate as sole carbon source, and into the tricarboxylic acid cycle, yielding finally phosphoenolpyruvate, the precursor of pyruvate and the triose phosphate derivatives [16]. They were also confirmed by incorporation of ${ }^{13} \mathrm{C}$-labeled glucose into isoprenoids from bacteria utilizing glucose via the Embden-Meyerhof-Parnas pathway and by studies in other isoprenoid series such as the ubiquitous ubiquinones and menaquinones [16]. Incorporation of doubly labeled $\left[4,5-{ }^{13} \mathrm{C}_{2}\right]$ glucose into the hopanoids and ubiquinone of Methylobacterium fujisawaense and of uniformly labeled $\left[\mathrm{U}_{-}{ }^{13} \mathrm{C}_{6}\right]$ glucose into the hopanoids from $Z$. mobilis afforded a definitive proof for the formation of the isoprene units via $\mathrm{C}_{2}$ and a $\mathrm{C}_{3}$ subunit and shed light on a rearrangement reaction allowing the insertion of the $\mathrm{C}_{2}$ subunit derived from pyruvate $\mathbf{1 1}$ between two carbon atoms from the triose phosphate-derived $\mathrm{C}_{3}$ subunit $[16,17]$. This triose phosphate was identified as glyceraldehyde phosphate $\mathbf{1 0}$ by feeding $E$. coli mutants lacking each enzymes of the triose phosphate metabolism with either ${ }^{13} \mathrm{C}$-labeled glycerol in the presence of unlabeled pyruvate, or ${ }^{13} \mathrm{C}$-labeled pyruvate in the presence of unlabeled glycerol [17]. A hypothetical biogenetic pathway was proposed, including as first step a reaction involving a transketolase-like, thiamin diphosphate-dependent enzyme catalyzing the condensation of hydroxyethylthiamin derived from pyruvate decarboxylation on the carbonyl group of a triose phosphate derivative and a second step with an $\alpha$-ketol rearrangement resembling the reaction catalyzed by the acetolactate isomero-reductase followed by the concomitant reduction of the resulting aldehyde and yielding methylerythritol 4-phosphate 22 (MEP) [16,17]. MEP presents the characteristic branched $\mathrm{C}_{5}$ skeleton of all isoprenoids and has to be considered as a hemiterpene. The pathway was named after this intermediate, which has to date no other known role than that of an isoprenoid precursor and which most probably is the result of a committed step of the pathway.

\section{UBIQUITOUS PRESENCE OF THE MEP PATHWAY IN CHLOROPLASTS OF PHOTOTROPHIC ORGANISMS}

Once an alternative route for isoprenoid biosynthesis has been found in bacteria, it was tempting to check whether such a pathway is involved in the formation of plant isoprenoids such as carotenoids, phytol, mono- and diterpenes. Indeed, independent IPP formation was formerly pointed out in plant chloroplasts, and the presence of an alternative route would be consistent with the discrepancies with respect to the MVA pathway mentioned above.

Labeling experiments using ${ }^{13} \mathrm{C}$-labeled glucose isotopomers were performed on ginkgo embryos by Schwarz and Arigoni, independently of our own assays with bacteria, and afforded the first proof for the presence of the MEP pathway in plants $[18,19]$. They resulted in labeling patterns of ginkgolides 8 (Fig. 1), belonging to a diterpenoid series, which could be interpreted in the frame of the same biogenetic pathway as that proposed for the formation of bacterial isoprenoids (Fig. 3). They also shed light on the dichotomy in the isoprenoid biosynthesis in plant cells: the mevalonate pathway is involved, as expected, in the sterol biosynthesis in the cytoplasm, whereas isoprenoids that are most likely plastid related are synthesized via the MEP pathway [18]. Incorporation of ${ }^{13} \mathrm{C}$-labeled glucose into the isoprenoids from several higher plant systems afforded additional proofs for the presence of the MEP pathway in plants. The ubiquitous terpenoids of the photosynthetic apparatus (carotenoids $\mathbf{7}$, phytol 5 from chlorophyll, and the prenyl chain of plastoquinone 6) are also derived from the MEP pathway [20]. Finally, labeling experiments, performed with ${ }^{13} \mathrm{C}$-labeled glucose or with deuterium-labeled deoxyxylulose, showed the wide distribution of the MEP pathway. It is involved in the formation of all investigated hemi- (e.g., isoprene 2, 2-methylbut-3-en-2-ol, dimethylallyl and the rest linked to aromatic rings) [21-23], mono- [23,24] and diterpenoids [25-27] and some sesquiterpenoids [28]. 


\section{TOWARD THE IDENTIFICATION OF INTERMEDIATES}

\section{1-Deoxyxylulose 5-phosphate}

From the origin of the carbon atoms in the isoprene units derived from the MEP pathway, as deduced from the ${ }^{13} \mathrm{C}$ glucose labeling experiments, a 1-deoxy-D-xylulose (DX) derivative 21 (Fig. 3) was a likely isoprenoid precursor. This pentulose was not an unknown natural product. It has been found in the fermentation broth of a Streptomyces sp. [29] and was known as precursor for pyridoxol phosphate and thiamin diphosphate in E. coli [30,31]. Efficient incorporation of deuterium-labeled DX isotopomers into the prenyl chain of ubiquinone and menaquinone of wild-type E. coli represented the first proof for the role of a DX derivative as isoprenoid precursor [32]. Similar experiments performed with other systems from bacteria or from plants confirmed this conclusion. The gene of the 1-deoxyxylulose5-phosphate (DXP) synthase ( $d x s$ or $i s p A)$ was rapidly identified in E. coli $[33,34]$ and in peppermint [35], and later in many other organisms, owing to its expected similarity with the transketolase genes. As predicted, the enzyme is thiamin diphosphate-dependent and utilizes GAP $\mathbf{1 0}$ and pyruvate $\mathbf{1 1}$ as substrates to yield DXP 21.

\section{2-C-Methylerythritol 4-phosphate and its derivatives}

2-C-Methyl-D-erythritol (ME) is a natural product found in several higher plants [3]. Its 2,4-cyclodiphosphate 25 (Fig. 3) is accumulated in large amounts by some gram-positive bacteria in oxidative stress conditions induced by one-electron transfer inhibitors such as benzylviologen [3]. According to its structure, this tetrol fits well into the biogenetic scheme. It was, therefore, tempting to check whether ME is an isoprenoid precursor. Incorporation of ${ }^{13} \mathrm{C}$-labeled glucose showed that the carbon skeleton of ME from Corynebacterium ammoniagenes is synthesized via the same reaction sequence as the isoprene units of the menaquinones [36]. Deuterium-labeled ME was incorporated by wild-type $E$. coli into the prenyl chain of ubiquinone and menaquinone with a localization of the labeling in accord with the hypothetical biogenetic scheme [37]. This allowed the search for E. coli mutants auxotrophic for ME. Analysis of such mutants was followed by the discovery of the DXP isomero-reductase gene $(d x r$ or ispB) [38]. This enzyme catalyzes, as predicted, the acid-catalyzed $\alpha$-ketol rearrangement of DXP as well as the reduced nicotinamide adenine dinucleotide phosphate (NADPH)-dependent concomitant reduction of the resulting aldehyde, yielding MEP 22 as reaction product. The enzyme requires a divalent cation $\left(\mathrm{Co}^{2+}, \mathrm{Mg}^{2+}\right.$, or $\left.\mathrm{Mn}^{2+}\right)$ for catalysis.

The next three steps correspond to an activation of MEP, yielding three novel intermediates. Incubation of ${ }^{3} \mathrm{H}$-labeled MEP in the presence of nucleotide triphosphate with crude cell-free systems from E. coli resulted in the formation of a novel metabolite. The purification and identification of this novel radiolabeled metabolite was, however, difficult. The search in databases for genes encoding enzymes using a polyol phosphate (such as MEP) and a nucleotide triphosphate as substrate revealed the homology of a gene encoding an enzyme catalyzing the formation of $5^{\prime}$-diphosphocytidyl ribitol from cytidine 5 -triphosphate and from ribitol 5-phosphate and of a gene of unknown function in $E$. coli ( $y g b P$ or ispC). Cloning and overexpression of the E. coli ygbP gene resulted in the identification of an enzyme using MEP and cytidine triphosphate as substrates, yielding 4-diphosphocytidyl ME 23 as reaction product [39]. Whereas all other genes of the MEP pathway are scattered in the E. coli genome, this gene forms a small operon with the two next ones. This feature facilitated their identification. The enzyme encoded by the $y c h B$ (or $i s p D$ ) gene catalyzes the adenosine $5^{\prime}$-triphosphate (ATP)-dependent phosphorylation of the tertiary hydroxy group of 4-diphosphocytidyl ME yielding 4-diphosphocytidyl ME 2-phosphate 24 [40], and that encoded by $y c h B$ (or ispE) the formation of ME cyclodiphosphate 25 from the former intermediate with elimination of cytidine $5^{\prime}$-monophosphate (CMP) [41]. The three novel intermediates were incorporated into carotenoids by red pepper chromoplasts, suggesting that they corresponded to intermediates of the MEP pathway [39-41]. The latter three genes were also identified by another approach. In an E. coli strain capable of utilizing MVA after introduction of the genes 
permitting its conversion into IPP (MVA kinase, phosphomevalonate 17 kinase, and diphosphomevalonate $\mathbf{1 8}$ decarboxylase), random mutations, which were rescued by the addition of MVA to the culture medium allowed the identification of the $y g b P, y c h B$, and $y g b B$ genes and indicated that they are essential genes of the MEP pathway [42-44].

\section{ORIGIN OF HYDROGEN ATOMS IN ISOPRENE UNITS DERIVED FROM MEP PATHWAY: INDEPENDENT IPP AND DMAPP BIOSYNTHESIS}

The formation of allylic alcohol diphosphates such as IPP 19 and DMAPP 20 from an ME derivative (a tetrol) is not an obvious process. In order to get more insight into the steps downstream of ME cyclodiphosphate, more information was required. Knowledge on the fate of the hydrogen atoms in the pathway was expected to afford useful clues for the further elucidation of the MEP pathway.

Labeling experiments using deuterated DX isotopomers and a wild-type E. coli or deuterated ME isotopomers and an E. coli mutant with no functional deoxyxylulose phosphate synthase $d x s$ gene showed that no apparent changes occurred at the level of the carbon atoms corresponding to $\mathrm{C} 1, \mathrm{C} 4$, and C5 of IPP or DMAPP. All corresponding deuteriums from DX or from ME were preserved in the prenyl chains of ubiquinone 3 and menaquinone 4 [45-47].

Feeding of wild-type $E$. coli with $\left[4-{ }^{2} \mathrm{H}\right] \mathrm{DX} 27$ yielded a surprising labeling pattern of the prenyl chains (Fig. 4). The terminal isoprene units derived from DMAPP 20 and serving as starter for the elongation of the prenyl chain by the prenyl transferase showed considerable deuterium retention (up to $70 \%$ ), whereas all those derived from IPP 19 had no trace of deuterium [48]. This was confirmed by feeding [3,5,5,5- $\left.{ }^{2} \mathrm{H}_{4}\right] \mathrm{ME}$ to an $E$. coli strain with a deleted $d x s$ gene [47]. In such a strain, which has to be grown in the presence of free DX or ME, all isoprene units are derived from labeled precursor added to the culture medium. The expected retention of the three deuteriums of the ME methyl group was ob-<smiles>[R7][C@](O)(CO)C(O)C(C)=O</smiles>

27<smiles>[2H]/C(=C\CO)CO[Ga]O[Na]</smiles>

26<smiles>[R6][C@](O)(CO)[C@@]([2H])(O)CO</smiles>

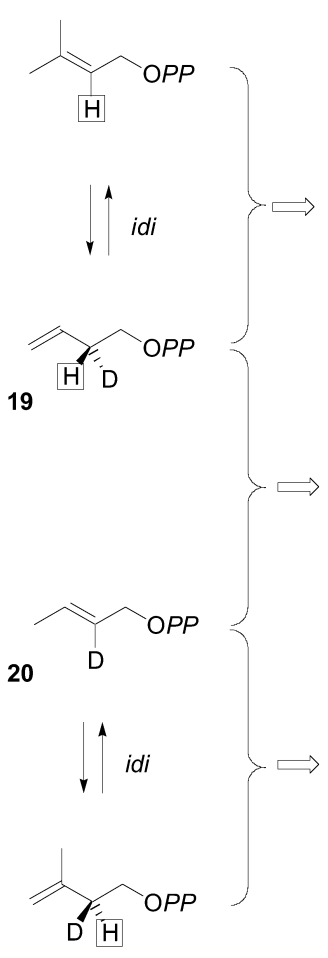

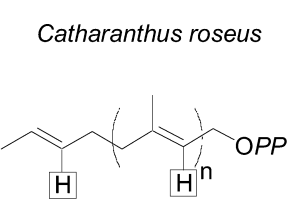

Escherichia coli Eucalyptus globulus

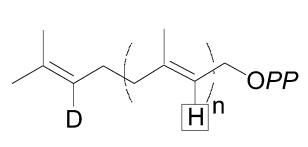

Tobacco BY-2

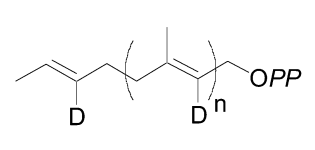

Fig. 4 Independent IPP and DMAPP biosynthesis in the MEP pathway. Incubation of $\left[4-{ }^{2} \mathrm{H}\right]-1$-deoxy-D-xylulose 27 or $\left[3-{ }^{2} \mathrm{H}\right]-2-C$-methyl-D-erythritol 28.

(C) 2003 IUPAC, Pure and Applied Chemistry 75, 375-387 
served, and their signal served as internal reference. The $3{ }^{2} \mathrm{H}$ was quantitatively retained only in the DMAPP 20 derived unit, whereas it was completely lost in those derived from IPP 19 (Fig. 4). Such a different labeling pattern in isoprene units, depending on their origin from IPP or from DMAPP, pointed to the possible presence of two branches leading separately to the two precursors of isoprene units. Furthermore, the activity of IPP isomerase is barely detectable in wild-type E. coli, and the deletion of the idi gene encoding the IPP isomerase does not affect the growth of the bacterium [49]. Definitive proof of the branching was obtained by a genetic method [50]. The deletion of the $d x r$ gene in E. coli is rescued either by the addition of free ME to the culture medium or by the introduction of the genes allowing the utilization of exogenous MVA. When the strain is growing on MVA, it only synthesizes IPP from MVA and has to rely on a functional protein capable of isomerizing IPP into DMAPP. If in addition the $i d i$ gene is deleted, the novel strain does not grow anymore on MVA, indicating that there is no other way in E. coli for converting IPP into DMAPP than the reaction catalyzed by the protein encoded by the idi gene. It grew, however, normally on ME. This shows that IPP and DMAPP can be independently synthesized from MEP derivative by two separate branches: an IPP branch characterized by deuterium loss from $\left[4-{ }^{2} \mathrm{H}\right] \mathrm{DX}$ or from $\left[3{ }^{2} \mathrm{H}\right] \mathrm{ME}$ and a DMAPP branch characterized by deuterium retention.

The fate of the 4-H hydrogen of DX can thus be utilized for the detection of a possible branching of the MEP pathway in plants (Fig. 4). Incubation of a Catharanthus roseus cell culture with $\left[1-{ }^{13} \mathrm{C}, 4-{ }^{2} \mathrm{H}\right] \mathrm{DX}$ resulted in ${ }^{13} \mathrm{C}$ labeling of all isoprene units with no trace of deuterium, suggesting that no branching occurred, at least in the utilized culture conditions [51]. Feeding of $\left[4{ }^{2} \mathrm{H}\right] \mathrm{DX}$ to eucalyptus twiglets was followed by a slight $(0.9 \%)$ but significant deuterium incorporation into the monoterpene cineol, but only in the DMAPP-derived moiety, with nearly no deuterium found in the isoprene unit derived from IPP [52]. Finally, incorporation of $\left[4-{ }^{2} \mathrm{H}\right] \mathrm{DX}$ into the plastid isoprenoids from a tobacco BY-2 cell culture resulted in the labeling of all isoprene units of phytoene and plastoquinone, whatever their origin from IPP or from DMAPP was, with the same isotope abundance (ca. 15\%) [53]. These experiments revealed the presence of the branching in plant cells. In C. roseus, only the IPP branch was detected. In eucalyptus, like in E. coli, both IPP and DMAPP branches were found. In tobacco, the DMAPP branch significantly contributed to the formation of all isoprene units. Definitive interpretation of the labeling patterns was only possible once more insight into the reduction reactions involved in the last two steps has been obtained.

\section{LAST STEPS: FROM METHYLERYTHRITOL CYCLODIPHOSPHATE TO IPP AND DMAPP}

Two additional genes, $g c p E$ (or $i s p G$ ) and $l y t B$ (or $i s p H$ ), were always found accompanying the formerly identified genes of the MEP pathway. Deletion of these genes was lethal for E. coli, but rescued by the insertion of the three genes allowing the utilization of exogenous mevalonate, indicating that they were implied in this biosynthetic route [54-56]. An E. coli strain with a deleted gcpE gene and capable of utilizing mevalonate accumulated methylerythritol cyclodiphosphate 25, suggesting that this intermediate is the substrate of the corresponding GcpE enzyme [57]. Crude cell-free systems from an E. coli strain overexpressing the biosynthesis of GcpE were capable of converting ME cyclodiphosphate 25 into (E)-4-hydroxy-2-methylbut-2-enyl diphosphate 25 (HMBPP) [58]. This protein was later shown to possess an oxygen-sensitive [4Fe-4S] cluster involved in a reductive process corresponding to two successive one-electron transfers [59]. Regeneration of the reducing system could be performed either by flavodoxin/flavodoxin reductase/NADPH or by deazaflavin via the semiquinone radical [59]. The accumulation of HMBPP 26 in a lyt $B$-deficient $E$. coli mutant strongly suggested that HMBPP is the substrate of the LytB protein [60]. A different approach also shed light on the role of the $g c p E$ gene. An $E$. coli strain overexpressing the gene of the xylulose kinase, an enzyme capable of phosphorylating free DX, and all genes encoding enzymes located upstream of the GcpE protein in the MEP pathway accumulated ME cyclodiphosphate upon incubation with uniformly ${ }^{13} \mathrm{C}$-labeled DX [61]. This experimen- 
tal procedure allowed the detection of intermediates by directly running the ${ }^{13} \mathrm{C}$ NMR spectra on crude cell-free systems. Additional overexpression of the GcpE gene was followed by the accumulation of HMBPP 26 [61] and of LytB resulted in the simultaneous formation of IPP 19 and DMAPP 20 [62]. This represented the first indication that the LytB protein was responsible for the conversion of HMBPP 26 into IPP 19 and DMAPP 20 and that the reaction catalyzed by this protein corresponds to the branching previously described. Finally incubation of ${ }^{3} \mathrm{H}$-labeled HMBPP with chromoplast from Capsicum annuum and Narcissus pseudonarcissus led to the formation of radiolabeled carotenoids, confirming the role of HMBPP 26 as intermediate in the MEP pathway [63].

\section{CHARACTERIZATION OF REDUCTION STEPS}

Z. mobilis proved a useful organism for the elucidation of the MEP pathway. In this bacterium, which has no complete tricarboxylic acid cycle, the reducing agent pool derived from NADPH or reduced nicotinamide adenine dinucleotide (NADH) results from three reactions of the glucose catabolism: the oxidation of glucose 6-phosphate into gluconolactone 6-phosphate, the oxidation of glyceraldehyde 3phosphate into phosphoglyceric acid and the reduction of acetaldehyde into ethanol. When $\left[1{ }^{2} \mathrm{H}\right] \mathrm{glu}-$ cose is utilized as sole carbon and energy source, a pool of the two possible isotopomers of ${ }^{2} \mathrm{H}$-labeled $\mathrm{NADPH} / \mathrm{NADH}$ in equivalent amounts results from the conjugate action of the three former enzymes. Accordingly, a ${ }^{2} \mathrm{H}$ transfer should characterize the reduction steps. After growing Z. mobilis on [1${ }^{2} \mathrm{H}$ ]glucose, two deuterium-labeled sites were characterized in the isoprene units of the hopanoids [64]. The first one corresponded to all carbon atoms derived from C4 of IPP or DMAPP. This labeling was introduced by the well-documented reduction step catalyzed by the NADPH-dependent DXP reductoisomerase. The second site corresponded to carbon atoms derived from $\mathrm{C} 2$ and represented the signature of an additional reduction step, which was later shown to be catalyzed by the LytB protein. As the next two enzymes implied in isoprenoid biosynthesis, the IPP isomerase and the prenyl transferase, eliminate both the pro- $R$ hydrogen of IPP, it is possible to propose a nearly complete hypothetical biogenetic scheme for the MEP pathway, including an interpretation for the different labeling patterns obtained after incubation of deuterium-labeled DX or ME (Fig. 4) [53].

\section{CONCLUSION: DISTRIBUTION OF THE PATHWAYS FOR ISOPRENOID BIOSYNTHESIS-THE MEP PATHWAY, A TARGET FOR NEW BIOCIDES}

The MEP pathway is nearly completely elucidated, and its distribution is now fairly well known [65-68]. MVA and MEP pathways can be usually readily differentiated by the labeling pattern resulting from the incorporation of ${ }^{13} \mathrm{C}$-labeled glucose (Figs. 2 and 3). The MEP metabolic route is present in most investigated bacteria. Its presence was detected either directly by biochemical proofs obtained after incubation of ${ }^{13} \mathrm{C}$-labeled carbon sources and analyzing the labeling pattern of the isoprenoids or via computer search of the genes encoding the enzymes of the pathway. Distribution of the MEP pathway in eubacteria does not clearly fit with the phylogeny and is interpreted in terms of lateral gene transfer [69,70]. Several Streptomyces spp. possess both pathways [71]. In this case, they are not expressed simultaneously. The MEP pathway is implied is the biosynthesis of essential metabolites such as the prenyl chains of the menaquinones 4 (Fig. 1), whereas the MVA route is utilized for the formation of the prenyl moiety of secondary metabolites with antibiotic activity.

The MEP pathway is also present in all phototrophic organisms. In higher plants and most algae, there is a dichotomy in the isoprenoid biosynthesis $[18,65,66]$. The MVA pathway is located in the cytoplasm and is responsible for the formation of sterols $\mathbf{9}$, triterpenes, the prenyl chain of ubiquinone $\mathbf{3}$ and most sesquiterpenoids $[3,66,72]$. The presence of the MEP pathway in contrast is restricted to the chloroplasts. This is evidenced by the specific labeling pattern of typical chloroplast isoprenoids from the photosynthetic apparatus (phytol 5 from chlorophylls, plastoquinone $\mathbf{6}$, carotenoids 7) [20] or sec- 
ondary metabolites, whose biosynthesis is related to plastid-like structures (isoprene 1, monoterpenes, diterpenes) [23-28]. Definitive proof for the localization of the MEP pathway in chloroplasts is given by the presence of a nucleotide sequence corresponding to a plastid-targeting peptide in the genes encoding the plant enzymes of the MEP pathway [35,73-77]. In unicellular green algae, however, no dichotomy in the isoprenoid biosynthesis was observed [78]. All isoprenoids, including the sterols from the cytoplasm, are derived from the MEP pathway. The clear-cut separation of the two biosynthetic routes to isoprenoids in plants is a simplified presentation. Cross-talk between the two compartments, cytoplasm and chloroplasts, and exchange of metabolites (IPP, DMAPP, geranyl diphosphate, and/or farnesyl diphosphate) were often observed and are probably a way for the regulation of isoprenoid biosynthesis to be explored [18,28,51]. Finally, the MEP pathway is also present in nonphototrophic eukaryotes, but belonging to phyla related to phototrophic unicellular eukaryotes. This is clearly the case for the parasite responsible for malaria, Plasmodium falciparum, and for related species, which are all characterized by the presence of apicoplasts, representing a residual chloroplast structure [79].

The MEP pathway is present in many pathogenic bacteria, in opportunistic pathogenic bacteria responsible for severe infections in immunodeficient patients and in the parasite responsible for malaria $[79,80]$. This means that all enzymes of this pathway are targets for inhibitors, which represent a novel class of antibacterial or antiparasitic drugs [79,81]. This novel and unexpected aspect is rather interesting in a context of increasing antibiotic and drug resistance of bacteria as well as of the malaria parasite.

\section{NOTE ADDED IN PROOF}

Additional information concerning the last two steps of the MEP pathway was recently made available [82-85]. Both GcpE and LytB proteins possess a [4Fe-4S] cluster as prosthetic group. A spectrophotometric enzyme test was described for both enzymes using dithionite as reducing agent $[82,83]$. Purified LytB catalyzes the reduction of HMBP 26 into IPP 19 and DMAPP 20 via two successive one-electron transfers and protonation of the resulting allylic anion. Much like for GcpE, the reduction may be performed either chemically by the 5-deazaflavin semiquinone radical, or by the flavodoxin/flavodoxin reductase/NADPH system $[84,85]$. The active reduced form of the LytB $[4 \mathrm{Fe}-4 \mathrm{~S}]^{1+}$ cluster was directly characterized by electron paramagnetic resonance after reconstitution of the prosthetic group in the purified enzyme and reduction with dithionite [85].

\section{REFERENCES}

1. K. Bloch. Steroids 57, 378-383 (1992).

2. D. A. Bochar, J. A. Friesen, C. V. Stauffacher, V. W. Rodwell. In Comprehensive Natural Product Chemistry. Isoprenoids Including Carotenoids and Isoprenoids, D. E. Cane (Ed.), Vol. 2, pp. 15-44, Pergamon, Oxford, UK (1999) and references therein.

3. M. Rohmer. In Comprehensive Natural Product Chemistry. Isoprenoids Including Carotenoids and Steroids, D. E. Cane (Ed.), Vol. 2, pp. 45-67, Pergamon, Oxford, UK (1999) and references therein.

4. K. S. Treharne, E. I. Mercer, T. W. Goodwin. Biochem. J. 99, 239-245 (1966).

5. D. V. Banthorpe, B. V. Charlwood, M. J. O. Francis. Chem. Rev. 72, 115-155 (1972).

6. T. J. Bach and H. K. Lichtenthaler. In Ecology and Metabolism of Plant Lipids, G. Fuller and W. D. Nes (Eds.), Vol. 325, 109-139, American Chemical Society, Washington, DC (1987).

7. T. J. Bach, A. Motel, T. Weber. Rec. Adv. Phytochem. 24, 1-82 (1990).

8. F. Lütke-Brinkhaus and H. Kleinig. Planta 171, 406-411 (1987).

9. W. Kohl, A. Gloe, H. Reichenbach. J. Gen. Microbiol. 129, 1629-1635 (1983).

10. G. Britton, T. W. Goodwin, W. S. J. Lockley, A. P. Mundy, N. J. Patel. Chem. Commun. 27-28 (1979). 
11. N. Orihara, K. Furihata, H. Seto. J. Antibotics 50, 979-981 (1997), and references therein.

12. S. Pandian, S. Saengchan, T. S. Raman. Biochem. J. 295, 675-691 (1981).

13. D. Zhou and R. H. White. Biochem. J. 273, 627-634 (1991).

14. G. Flesch and M. Rohmer. Eur. J. Biochem. 175, 405-411 (1988).

15. M. Rohmer. Pure Appl. Chem. 65, 1293-1298 (1993).

16. M. Rohmer, M. Knani, P. Simonin, B. Sutter, H. Sahm. Biochem. J. 295, 517-524 (1993).

17. M. Rohmer, M. Seemann, S. Horbach, S. Bringer-Meyer, H. Sahm. J. Am. Chem. Soc. 118, 2564-2566 (1996).

18. M. Schwarz. Ph.D. Thesis Nb 10951. Eidgenössische Technische Hochschule, Zürich, Switzerland (1994).

19. M. Schwarz and D. Arigoni. In Comprehensive Natural Product Chemistry. Isoprenoids Including Carotenoids and Steroids, D. E. Cane (Ed.), Vol. 2, pp. 367-340, Pergamon, Oxford, UK (1999) and references therein.

20. H. K. Lichtenthaler, J. Schwender, A. Disch, M. Rohmer. FEBS Lett. 400, 271-274 (1997).

21. J. G. Zeidler, H. K. Lichtenthaler, H. U. May, F. W. Lichtenthaler. Z. Naturforsch. 52c, 15-23 (1997).

22. J. G. Zeidler and H. K. Lichtenthaler. Planta 213, 323-326 (2001).

23. A. J. Barlow, H. Becker, K. P. Adam. Phytochemistry 57, 7-14 (2001).

24. W. Eisenreich, S. Sagner, M. H. Zenk, A. Bacher. Tetrahedron Lett. 38, 3889-3892 (1997).

25. W. Eisenreich, B. Menhard, P. J. Hylands, M. H. Zenk, A. Bacher. Proc. Natl. Acad. Sci. USA 93, 6431-6436 (1996).

26. W. Knöss, B. Reuter, J. Zapp. Biochem. J. 326, 449-454 (1997).

27. N. Totté, L. Charon, M. Rohmer, F. Compernolle, I. Baboeuf, J. M. C. Geuns. Tetrahedron Lett. 41, 6407-6410 (2000).

28. K.P. Adam and J. Zapp. Phytochemistry 48, 953-959 (1998).

29. H. Hoeksema and L. Baczynskyj. J. Antibiotics 29, 688-690 (1976).

30. S. David, B. Estramareix, J. C. Fischer, M. Thérisod. J. Am. Chem. Soc. 103, 7341-7342 (1981).

31. D. E. Cane, S. C. Du, J. K. Robinson, Y. J. Hsiung, I. D. Spenser. J. Am. Chem. Soc. 121, 7722-7723 (1999).

32. S. T. J. Broers. Ph.D. Thesis Nb. 10978. Eidgenössische Technische Hochschule, Zürich, Switzerland (1994).

33. G. A. Sprenger, U. Schörken, T. Wiegert, S. Grolle, A. A. de Graaf, S. V. Taylor, T. P. Begley, S. Bringer-Meyer, H. Sahm. Proc. Natl. Acad. Sci. USA 94, 12857-12862 (1997).

34. L. M. Lois, N. Campos, S. Rosa-Putra, K. Danielsen, M. Rohmer, A. Boronat. Proc. Natl. Acad. Sci. USA 95, 2105-2110 (1998).

35. B. M. Lange, M. R. Wildung, D. McCaskill, R. Croteau. Proc. Natl. Acad. Sci. USA 95, 2100-2104 (1998).

36. T. Duvold, J. M. Bravo, C. Pale-Grosdemange, M. Rohmer. Tetrahedron Lett. 38, 4769-4772 (1997).

37. T. Duvold, P. Calí, J. M. Bravo, M. Rohmer. Tetrahedron Lett. 38, 6181-6184 (1997).

38. S. Takahashi, T. Kuzuyama, H. Watanabe, H. Seto. Proc. Natl. Acad. Sci. USA 95, 9879-9884 (1998).

39. F. Rohdich, J. Wungsintaweekul, W. Eisenreich, G. Richter, C. A. Schuhr, S. Hecht, M. H. Zenk, A. Bacher. Proc. Natl. Acad. Sci. USA 97, 6451-6456 (2000).

40. H. Lüttgen, F. Rohdich, S. Herz, J. Wungsintaweekul, S. Hecht, C. A. Schuhr, M. Fellermeier, S. Sagner, M. H. Zenk, A. Bacher, W. Eisenreich. Proc. Natl. Acad. Sci. USA 97, 1062-1067 (2000).

41. S. Herz, J. Wungsintaweekul, C. A. Schuhr, S. Hecht, H. Lüttgen, S. Sagner, M. Fellermeier, W. Eisenreich, M. H. Zenk, A. Bacher, F. Rohdich. Proc. Natl. Acad. Sci. USA 97, 2486-2490 (2000). 
42. T. Kuzuyama, M. Takagi, K. Kaneda, T. Dairi, H. Seto. Tetrahedron Lett. 41, $403-706$ (2000).

43. T. Kuzuyama, M. Takagi, K. Kaneda, H. Watanabe, T. Dairi, H. Seto. Tetrahedron Lett. 41, 2925-2928 (2000).

44. M. Takagi, T. Kuzuyama, K. Kaneda, H. Watanabe, T. Dairi, H. Seto. Tetrahedron Lett. 41, 3395-3398 (2000).

45. T. Duvold. Ph.D. Thesis. Université Louis Pasteur, Strasbourg, France (1997).

46. J. L. Giner and B. Jaun. Tetrahedron Lett. 39, 8021-8022 (1998).

47. L. Charon, J. F. Hoeffler, C. Pale-Grosdemange, L. M. Lois, N. Campos, A. Boronat, M. Rohmer. Biochem. J. 346, 737-742 (2000).

48. J. L. Giner, B. Jaun, D. Arigoni. Chem. Commun. 717-718 (1998).

49. F. M. Hahn, A. P. Hurlburt, C. D. Poulter. J. Bacteriol. 181, 4499-4504 (1991).

50. M. Rodríguez-Concepción, N. Campos, L. M. Lois, C. Maldonaldo, J. M. Hoeffler, C. Grosdemange-Billiard, M. Rohmer, A. Boronat. FEBS Lett. 465, 157-160 (2000).

51. D. Arigoni, W. Eisenreich, C. Latzel, S. Sagner, T. Radykewicz, M. H. Zenk, A. Bacher. Proc. Natl. Acad. Sci. USA 96, 1309-1314 (1999).

52. C. Rieder, B. Jaun, D. Arigoni. Helv. Chim. Acta 83, 2504-2513 (2000).

53. J. F. Hoeffler, A. Hemmerlin, C. Grosdemange-Billiard, T. J. Bach, M. Rohmer. Biochem. J. 366, 573-583 (2002).

54. N. Campos, M. Rodríguez-Concepción, M. Seemann, M. Rohmer, A. Boronat. FEBS Lett. 488, $170-173$ (2001).

55. B. Altincicek, A. K. Kollas, S. Sanderbrand, J. Wiesner, M. Hintz, E. Beck, H. Jomaa. J. Bacteriol. 183, 2411-2416 (2001).

56. B. Altincicek, A. K. Kollas, M. Eberl, J. Wiesner, S. Sanderbrand, M. Hintz, E. Beck, H. Jomaa. FEBS Lett. 499, 37-40 (2001).

57. M. Seemann, N. Campos, M. Rodríguez-Concepción, J. F. Hoeffler, C. Grosdemange-Billiard, A. Boronat, M. Rohmer. Tetrahedron Lett. 43, 775-778 (2002).

58. M. Wolff, M. Seemann, C. Grosdemange-Billiard, D. Tritsch, N. Campos, M. RodríguezConcepción, A. Boronat, M. Rohmer. Tetrahedron Lett. 43, 2555-2559 (2002).

59. M. Seemann, B. Tse Sum Bui, M. Wolff, D. Tritsch, N. Campos, A. Boronat, A. Marquet, M. Rohmer. Angew. Chem. 41, 4337-4339 (2002).

60. M. Hintz, A. Reichenberg, B. Altincicek, U. Bahr, R. M. Gschwind, A. K. Kollas, E. Beck, J. Wiesner, M. Eberl, H. Jomaa. FEBS Lett. 509, 317-322 (2001).

61. S. Hecht, W. Eisenreich, P. Adam, S. Amslinger, K. Kis, A. Bacher, D. Arigoni, F. Rohdich. Proc. Natl. Acad. Sci. USA 98, 14837-14842 (2001).

62. F. Rohdich, S. Hecht, K. Gärtner, P. Adam, C. Krieger, S. Amslinger, D. Arigoni, A. Bacher, W. Eisenreich. Proc. Natl. Acad. Sci. USA 99, 1158-1163 (2002).

63. W. Gao, R. Loeser, M. Raschke, M. A. Dessoy, M. Fulhorst, H. Alpermann, L. A. Wessjohann, M. H. Zenk. Angew. Chem. 41, 2604-2607 (2002).

64. L. Charon, C. Pale-Grosdemange, M. Rohmer. Tetrahedron Lett. 40, 7231-7234 (1999).

65. M. Rohmer. Nat. Prod. Rep. 11, 565-574 (1999) and references therein.

66. H. K. Lichtenthaler. Annu. Rev. Plant Physiol. Plant Mol. Biol. 50, 46-65 (1999) and references therein.

67. F. Rohdich, K. Kis, A. Bacher, W. Eisenreich. Curr. Opinion Chem. Biol. 5, 535-540 (2001) and references therein.

68. W. Eisenreich, F. Rohdich, A. Bacher. Trends Plant Sci. 6, 78-84 (2001) and references therein.

69. Y. Boucher and W. F. Doolittle. Mol. Microbiol. 37, 703-716 (2000).

70. B. M. Lange, T. Rujan, W. Martin, R. Croteau. Proc. Natl. Acad. Sci. USA 97, 13172-13177 (2000).

71. H. Seto, H. Watanabe, K. Furihata. Tetrahedron Lett. 37, 7979-7982 (1996). 
72. A. Disch, A. Hemmerlin, T. J. Bach, M. Rohmer. Biochem. J. 231, 615-621 (1998).

73. B. M. Lange and R. Croteau. Arch. Biochem. Biophys. 365, 170-174 (1999).

74. F. Rohdich, J. Wungsintaweekul, W. Eisenreich, G. Richter, C. A. Schuhr, S. Hecht, M. H. Zenk, A. Bacher. Proc. Natl. Acad. Sci. USA 97, 6451-6456 (2000).

75. F. Rohdich, J. Wungsintaweekul, H. Lüttgen, M. Fischer, W. Eisenreich, C. A. Schuhr, M. Felleremeier, N. Schramek, M. H. Zenk, A. Bacher. Proc. Natl. Acad. Sci. USA 97, 8251-8256 (2000).

76. J. Querol, N. Campos, S. Imperial, A. Boronat, M. Rodríguez-Concepción. FEBS Lett. 514, 343-346 (2002).

77. F. X. Cunningham Jr., T. P. Lafond, E. Gantt. J. Bacteriol. 182, 5841-5848 (2000).

78. A. Disch, J. Schwender, C. Müller, H. K. Lichtenthaler, M. Rohmer. Biochem. J. 333, 381-388 (1998).

79. H. Jomaa, J. Wiesner, S. Sanderbrand, A. Altincicek, C. Weidemeyer, M. Hintz, I. Türbachova, M. Eberl, J. Zeidler, H. K. Lichtenthaler, D. Soldati, E. Beck. Science 285, 1573-1576 (1999).

80. S. Rosa-Putra, A. Disch, J. M. Bravo, M. Rohmer. FEMS Microbiol. Lett. 164, 169-175 (1998).

81. M. Rohmer. Progr. Drug Res. 50, 135-154 (1998).

82. A. K. Kollas, E. C. Duin, M. Eberl, B. Altincicek, M. Hintz, A. Reichenberg, D. Henschker, A. Henne, I. Steinbrecher, D. N. Ostrovsky, R. Hedderich, E. Beck, H. Jomaa, J. Wiesner. FEBS Lett. 532, 432-436 (2002).

83. B. Altincicek, E. C. Duin, A. Reichenberg, R. Hedderich, A. K. Kollas, M. Hintz, S. Wagner, J. Wiesner, E. Beck, H. Jomaa. FEBS Lett. 532, 437-440 (2002).

84. F. Rohdich, F. Zepeck, P. Adam, S. Hecht, J. Kaiser, R. Laupitz, T. Gräwert, S. Amslinger, W. Eisenreich, A. Bacher, D. Arigoni. Proc. Natl. Acad. Sci. USA 100, 1586-1591 (2003).

85. M. Wolff, M. Seemann, B. Tse Sum Bui, Y. Frapart, D. Tritsch, A. Garcia-Estrabot, M. Rodriguez-Concepcion, A. Boronat, A. Marquet, M. Rohmer. FEBS Lett. In press. 